\section{Gynecologic Cancer}

James A. Corscaden, PH.B., M.D. Third edition. Pp. xi +574 , illustrated. Baltimore: Williams and Wilkins. London: Baillière, Tindall and Cox. 1962. $96 s$.

This magnificent third edition is obviously the work of a born fighter imbued with the rare combination of knowledge and enthusiasm tempered by a fair-minded and judicial outlook.

In his preface he boldly states that the realization that most of the deaths of women from cancer of the reproductive organs are unnecessary will sooner or later strike the public mind. When or before this happens physicians must decide whether they will accept social responsibility and take steps to bring about a lessening of this wastage or whether they will be content to remain technicians, subject to the orders of those in power.

The introduction, written with great clarity, should be studied by all interested. Facts and figures are well presented, opposing views fairly given, and should cause most readers to consider their whole outlook anewthose who teach on their attitude to, and presentation of, the subject and those who treat the victims on the quality and extent of their clinical care.

He pleads eloquently and skilfully for earlier diagnosis of all reproductive cancers, emphasizes the uselessness of bleeding as an early symptom of cancer of the cervix, and stresses that the assumption that the bleeding which occurs during administration of cstrogens is due either to hyperplasia or to withdrawal may lead to disaster and therefore should not be allowed to continue without investigation.

'If we combine the physical examination, the Papanicolaou smear and the excision biopsy, the degree of accuracy is almost perfect in the diagnosis of cancer of the cervix'.

Cancer of the vulva is described as the most accessible yet the most neglected of all gynæcologic cancers. Delay in diagnosis is primarily the fault of the patient, but she is aided and abetted by the physician.

Leucoplakia is recognized as an important factor in the background of vulvar carcinoma, and the pruritus vulvæ which precedes the growth in $40 \%$ of cases is a definite indication for persistent systematic follow-up observation.

The reasons for performing routinely a total hysterectomy in benign conditions of the uterus are clearly stated, with the addendum that 'nulliparity is no protection from cancer of the cervix'. The choice of treatment in this latter condition is discussed and he concludes that 'intracavitary radium at this time is the standard form of treatment', but recommends radical hysterectomy in certain defined cases.

Discussing the opposing views on endometrial cancer, the author states his belief that some cases have been caused by therapeutic œstrogens, but that other uteri containing endometrial cancers show complete absence of evidence of any œstrogenic stimulation.

He concludes on a most hopeful note by asserting that, while the present survival rate in gynæcologic cancer is about $40 \%$, salvage can be raised to $80 \%$ by the systematic application of ordinary diagnostic techniques. By more elaborate techniques, such as the Papanicolaou smear, the rate can be raised to $95 \%$.

He pleads for more knowledge regarding the results following treatment, both well executed and otherwise. These are known in probably less than $10 \%$ of lesions treated. More money, energy and time must be spent in the assembling of this information, for these lesions carry with them the sentence of death.
This book is indispensable for all engaged in the fight against cancer of the reproductive organs, as much for its morale-raising quality as for its mature judgment and detailed knowledge backed by an enormous bibliography.

\section{Neurosecretion}

Edited by H. Heller and R. B. Clark. Memoirs of the Society for Endocrinology, No. 12. Proceedings of the Third International Symposium on Neurosecretion, held in the University of Bristol, September 1961. Pp. xv + 455. London and New York: Academic Press. 1962. 9os.

The concept of neurosecretion was initially based on the finding that certain cells in the central nervous system were ' Gomori positive', resembling in this respect elements in the posterior pituitary. In mammals the most important examples were the hypothalamic nuclei, which secrete vasopressin, oxytocin and hormones controlling the adenohypophysis. Subsequently, neurosecretion has become a wider but also more specific concept. Although electron microscopy has shown that most neurones contain secretory granules, nerve cells are now regarded as neurosecretory only if their axons do not form synapses with other cells, but end at blood spaces into which they release their secretions. Like other hormones, these secretions may then act on distant target organs. This definition excludes the formation at synapses of transmitter substances which act only locally. On the other hand, the cells of the adrenal medulla, although derived from the neural crest and undoubtedly delivering a hormone into the blood, are excluded because they do not possess axons and dendrites and are therefore not neurones.

The proceedings of the Bristol meeting are presented in four parts. The first is concerned with the ultrastructure of neurosecretory elements studied by electron microscopy. The other three parts deal with the histology and physiology of neurosecretory systems in vertebrates, annelids and arthropods, respectively. The diversity of the animal classes covered by the contributions fully justifies the separate species index. It will therefore be the reader with wider biological interests who will benefit most from the book. It contains a great deal of information, mostly of a morphological nature, on the questions currently asked by workers in this field. Which are the intracellular organelles responsible for the synthesis of the hormones? Do axons participate in the synthesis of the secretions or do they only transport them? What are the rate and mechanism of this axonal transport? Are the specific staining properties due to active peptides or to carrier proteins?

Several recent advances in the understanding of the physiological significance of neurosecretory systems are reported. Once again a function is claimed for the mammalian pineal gland: its cells secrete melatonin. In other classes processes controlled by neurosecretion include moulting, migration, seasonal gonadal cycles, metamorphosis, locomotion, wound healing and regeneration.

The book is well produced. The numerous photographs of electron and ordinary microscopy are admirably clear, mostly rather large in size and scale, and probably responsible for the price. 